\title{
PERANAN KOMITMEN ORGANISASI SEBAGAI MEDIASI TERHADAP EFEK ETIKA PERUSAHAAN KEPADA PERILAKU KEWARGAAN ORGANISASI Studi pada PT. Bank Aceh Syariah
}

\author{
MAHDANI IBRAHIM, SAED ARMIA DAN T. FADHILATUL AMRI \\ Fakultas Ekonomi dan Bisnis, Universitas Syiah Kuala, Banda Aceh
}

This research was conducted at Bank Aceh Syariah in Tapak Tuan with unit of analysis is employee. Research takes the area of human resource management and organization. The research aims to analyze the role of organizational commitment as a mediation variable to the effect of company ethics and $\mathrm{OCB}$, also analyze the direct influence between variables. The sample was taken with census method as many as 75 employees, the primary data was obtained by circulating the questionnaire. Data analysis using path analysis. The results showed that there is a role of mediation variable of $14.38 \%$, the direct effect between corporate ethics to OCB of $40.5 \%$. The role of organizational commitment variable is significant at level 0,000 and far $<0.005$. The effects of the variables tested and the theoretical and managerial implications are discussed in the discussion.

Keyword: Corporate Ethics, Organizational Commitment, $O C B$, Bank Aceh Syariah 


\section{PENDAHULUAN}

Perusahaan jasa keuangan bank seperti halnya PT. Bank Aceh Syariah memegang peranan penting dalam mendukung kegiatan ekonomi masyarakat. Hal ini disebabkan bank merupakan lembaga perantara antara masyarakat yang kelebihan dana di satu sisi dengan masyarakat yang membutuhkan dana di sisi lain. Sehingga dapat dikatagorikan sebagai lembaga yang memberikan pelayanan publik guna memenuhi kebutuhan masyarakat.

Terdapat perubahan yang signifikan dalam dinamika kerja pada organisasi yang terutamanya pada organisasi yang berorientasi profit. Kebanyakan organisasi yang berorientasi profit di banyak negara di dunia telah bergeser dari bekerja secara individual menjadi bekerja secara tim (work teams) (Diricana \& Erdilb, 2016). Kemampuan individual dalam sebuah tim akan menentukan efektivitas kinerja tim yang menjalankan suatu aktifitasnya. Akan tetapi sering ditemukan bahwa tidak semua orang mampu bekerja sama dalam tim, karena memerlukan berbagai kemampuan individu termasuk kemampuan berkomunikasi dengan baik yang dapat diterima oleh sebahagian besar anggota tim (Bai, Lin \& Wang, 2016). Tidak semua orang mampu bekerja sama dalam tim karena memerlukan kemampuan individu untuk berkomunikasi secara terbuka dan jujur, bekerja sama dengan orang lain, membagi informasi, mengakui perbedaan dan mampu menyelesaikan konflik, serta dapat menekan tujuan pribadi demi tujuan tim.

Dengan kata lain individu tersebut menampilkan perilaku extra-role. Perilaku extra-role adalah perilaku dalam bekerja yang tidak terdapat pada deskripsi kerja formal pegawai tetapi sangat dihargai jika ditampilkan pegawai karena meningkatkan efektivitas dan kelangsungan hidup organisasi. Perilaku extra-role dalam organisasi juga dikenal dengan istilah organizational citizenship behavior $(O C B)$, dan orang yang menampilkan perilaku OCB disebut sebagai karyawan yang baik (good citizen). Sehingga perilaku OCB dalam diri karyawan tidak hanya meningkatkan kelancaran kegiatan operasional perusahaan, akan tetapi lebih penting lagi menentukan keberhasilan perusahaan dalam mencapai tujuan yang telah ditetapkan.

Selanjutnya persepsi karyawan terhadap praktek etika perusahaan tempat mereka bekerja, di mana hal ini dapat memicu karyawan untuk bekerja dengan baik yang sesuai dengan ketentuan ang ada, atau juga sebalikna, karena tergantung pada cara perusahaan dalam menerapkan etika bisnis. Etika perusahaan terdiri dari etika eksternal, etika internal dan etika karyawan (Chun et al, 2013). Etika eksternal berkaitan dengan etika perusahaan terhadap lingkugan eksternal perusahaan seperti masyarakat dan stakeholder terkait lainnya yang berada diluar lingkungan perusahaan. Selanjutnya etika internal berkaitan dengan etika dalam perusahaan. Dalam hal ini antara lain meliputi peraturan kerja, prinsip-prinsip nilai etis perusahaan dan lain sebagainya. Terakhir, etika karyawan berkaitan dengan etika yang harus dijunjung tinggi oleh karyawan. (Barnett \& Vaicys, 2010; Jin \& Drozdenko, 2010).

PT. Bank Aceh Syariah Tapak Tuan dalam prakteknya dianggap masih belum menerapkan suatu etika perusahaan sebagaimana yang diharapkan oleh sebahagian besar karyawan. Oleh karena itu hal ini akan mempengaruhi kepada perilaku karyawan baik secara langsung maupun tidak langsung terhadap $O C B$. Setiap perusahaan tentunya mengharapkan karyawannya berperilaku sesuai dengan kontektual $O C B$. Tetapi dilain pihak perilaku perusahaan yang berkenaan dengan etika perusahaan belum sanggup dijalankan dengan baik.

Upaya peningkatan pelayanan bank guna memenuhi kebutuhan masyarakat tidak hanya disebabkan oleh semakin pentingnya peranan lembaga keuangan tersebut dalam menggerakan ekonomi masyarakat, tetapi juga disebabkan oleh semakin tingginya tingkat persaingan bisnis di antara sesama perusahaan jasa keuangan. Bank yang mampu memberikan pelayanan lebih baik dianggap dapat memenuhi kebutuhan masyarakat akan sangat diminati oleh nasabahnya. Sebaliknya bank yang dinilai memiliki pelayanan kurang baik akan ditinggalkan dan nasabah akan beralih ke bank lain yang mereka anggap lebih baik.

Upaya peningkatan kinerja dan pelayanan perusahaan jasa keuangan bank seperti halnya PT. Bank Aceh Syariah tidak terlepas dari dukungan 
karyawannya. Hal ini berarti, karyawan memegang kunci penting bagi perbaikan kinerja lembaga keuangan bank. Dalam prakteknya, setiap karyawan diharapkan mampu memiliki sikap dan perilaku yang mendukung upaya peningkatan kinerja bank yakni yang mengacu pada konsep $O C B$.

Perilaku karyawan dalam bekerja dapat dipengaruhi oleh berberapa faktor diantaranya komitmen organisasi kolektif dan penilaian mereka terhadap etika perusahaan. Komitmen organisasi adalah tingkat keterikatan individu pada organisasi tercermin dari: adanya keyakinan yang kuat dan penerimaan atas nilai dan tujuan organisasi, kesediaan untuk mengusahakan yang terbaik untuk organisasi, dan adanya keinginan yang pasti untuk mempertahankan keikutsertaan dalam organisasi. Komitmen organisasi kolektif mengacu pada adanya pola pikir kolektif dalam diri karyawan berkaitan dengan perilaku kerja secara umum dengan perasaan setia dan ingin mencurahkan tenaga dan pikiran mereka untuk membantu organisasi dalam mencapai tujuan yang telah ditetapkan (Meyer \& Allen, 2011). Dengan demikian komitmen organisasi kolektif pada dasarnya indentik dengan komitmen organisasi. PT. Bank Aceh Syariah Tapak Tuan perlu meningkatkan pemberdayaan karyawan dalam konteks komitmen organisasi sehingga para karyawan lebih merasa betah dan nyaman dalam menjalankan fungsinya setisap hari. Peneliti ingin melihat sejauh mana peranan komitmen organisasional yang telah diterapkan pada karyawan sehingga mampu memediasi kekurangan dalam etika perusahaan yang dipraktekkan yang pada gilirannya dapat meningkatkan persepsi $O C B$ dikalangan karyawan PT. Bank Aceh Syariah Tapak Tuan.

\section{Pertanyaan Penelitian}

1. Apakah etika perusahaan berpengaruh terhadap perilaku kewargaan organisasi PT. Bank Aceh Syariah Tapak Tuan.

2. Apakah komitmen organisasi memiliki peran mediasi terhadap pengaruh etika perusahaan dan perilaku $O C B$ pada PT. Bank Aceh Syariah Tapak Tuan.

\section{Tujuan Penelitian}

1. Menganalisis dan mengatahui pengaruh etika perusahaan terhadap perilaku kewargaan organisasi PT. Bank Aceh Syariah Tapak Tuan.

2. Menganailisis dan mengetahui sejauh mana peranan komitmen organisasi dalam memediasi pengaruh etika perusahaan terhadap perilaku OCB pada PT. Bank Aceh Syariah Tapak Tuan.

\section{KAJIAN PUSTAKA}

\section{Perilaku Kewargaan Organisasi/OCB}

Perilaku kewargaan organisasi yang dalam bahasa Inggris disebut dengan Organizational Citizenship Behavior (OCB) merupakan istilah yang digunakan untuk mengidentifikasi perilaku karyawan. Perilaku kewargaan organisasi didefinisikan sebagai perilaku yang menguntungkan organisasi atau berniat menguntungkan organisasi yang secara langsung mengarah pada peran pengharapan (Huang \& Yang, 2014). Selain itu, perilaku kewargaan organisasi juga dapat diartikan sebagai sikap membantu yang ditunjukkan oleh anggota organisasi, yang sifatnya konstruktif, dihargai oleh perusahaan tapi tidak secara langsung berhubungan dengan produktivitas individu (Purba \& Nina, 2014).

Berdasarkan konsep di atas, maka perilaku kewargaan organisasi juga merupakan kontribusi individu yang melebihi tuntutan organisasi di mana karyawan sebagai pekerjanya. Perilaku tersebut melibatkan beberapa perilaku meliputi perilaku sukan membantu kawan sekerja lain, menjadi sukarelawan untuk tugas-tugas ekstra, dan patuh terhadap aturan-aturan dan prosedur-prosedur ditempat kerja. Perilaku-perilaku ini menggambarkan "nilai tambah karyawan" yang merupakan salah satu bentuk perilaku prososial, yaitu perilaku sosial yang aktif, konstruktif dan bermakna positif (Robbins, 2012:123).

\section{Etika Perusahaan}

Kode etik atau etika perusahaan dapat dlihat sebagai prinsip, etika, aturan (rules of conducts), aturan praktek, atau filosofi mengenai tanggung jawab kepada stakeholders, lingkungan, atau aspek-aspek kemasyarakatan lainnya yang berada di luar lingkungan perusahaan (Kapstein, 2014). Kapstein menambhakan bahwa etika perusahaan 
mengklarifikasi tujuan yang hendak dicapai oleh perusahaan, norma-norma dan nilai-nilai yang dipegang dan apa yang dapat diperjuangkan agar akuntabel. Etika mencakup tanggung jawab, prinsip, nilai dan/atau norma yang dimiliki oleh perusahaan. Sehingga etika juga menunjukkan kepekaan/kepedulian sebuah perusahaan terhadap isu-isu etika dan menunjukkan bagaimana perusahaan tersebut menyikapi topik-topik yang terkait dengan persoalan di atas.

Etika perusahaan juga dapat diartikan sebagai persepsi karyawan terhadap praktek etika perusahaan tempat mereka bekerja (Barnett \& Vaicys, 2010; Jin \& Drozdenko, 2010). Tsai dan Huang (2014) menyatakan bahwa persepsi terhadap etika perusahaan merupakan prediktor penting bagi perilaku karyawan di tempat kerja. Selain itu persepsi terhadap etika perusahaan juga dapat mempengaruhi outcome pekerjaan termasuk kepuasan kerja. Sedangkan Cullen et al. (2013) dan Schwepker (2011) menyatakan bahwa persepsi karyawan terhadap etika perusahaan dapat mempengaruhi komitmen organisasi atau rasa keterikatan karyawan terhadap organisasi tempat mereka bekerja.

\section{Komitmen Organisasi}

Malthis dan Jackson (2012:233) mendefinisikan, "organizational commitment is the degree to which employees believe in and accept organizational goals and desire to remain with the organization" (Komitmen organisasional adalah derajat yang mana karyawan percaya dan menerima tujuan-tujuan organisasi dan akan tetap tinggal atau tidak akan meninggalkan organisasi. Lebih lanjutnya dijelaskan bahwa komitmen adalah "tingkat kepercayaan dan penerimaan tenaga kerja terhadap tujuan organisasi dan mempunyai keinginan untuk tetap ada di dalam organisasi tersebut yang pada akhirnya tergambar dalam statistik ketidakhadiran dan masuk keluar tenaga kerja (turnover).

Selanjutnya Mowday seperti yang dikutip oleh Sopiah (2014:155) menyatakan, komitmen organisasional merupakan dimensi perilaku penting yang dapat digunakan untuk menilai kecenderungan karyawan untuk bertahan sebagai anggota organisasi. Komitmen organisasional merupakan identifikasi dan keterlibatan seseorang yang relatif kuat terhadap organisasi. Komitmen organisasional adalah keinginan anggota organisasi untuk tetap mempertahankan keanggotaannya dalam organisasi dan bersedia berusaha keras bagi pencapaian tujuan organisasi.

Kreitner dan Angelo (2015:274) menyatakan, komitmen organisasi mencerminkan bagaimana seseorang individu mengidentifikasikan dirinya dengan organisasi dan terikat dengan tujuan-tujuannya. Selanjutnya, Mobley et.al dalam Malthis dan Jackson (2012:235) menyatakan sebagai berikut:

Komitmen karyawan terhadap organisasi secara umum dapat didefinisikan sebagai tingkat keterikatan individu kepada organisasi tertentu yang tercermin dengan karakteristik: a) Adanya keyakinan yang kuat dan penerimaan atas nilai dan tujuan organisasi, b) Kesediaan untuk mengusahakan yang terbaik untuk organisasi, dan c) Adanya keinginan yang pasti untuk mempertahankan keikutsertaan dalam organisasi. Dengan demikian karyawan yang menunjukkan tingkat komitmen organisasional yang tinggi akan mempunyai tingkat keinginan berpindah kerja yang rendah.

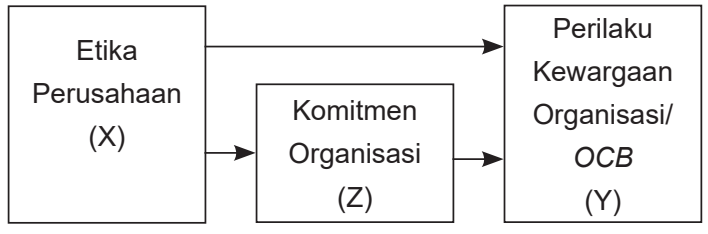

Gambar 1. Kerangka Penelitian

\section{METODE PENELITIAN}

\section{Populasi dan Sampel}

Populasi dalam penelitian ini adalah seluruh karyawan PT. Bank Aceh Syariah cabang Tapak Tuan pada periode tahun 2017 yang berjumlah 78 orang. Karena populasi relatif kecil dan memungkinkan peneliti untuk meneliti seluruh populasi, maka keseluruhan jumlah pegawai tersebut dijadikan sampel penelitian, sehingga metode penarikan sampel yang digunakan adalah metode sensus.

\section{Teknik Pengumpulan Data}

Teknik pengumpulan data premer dilakukan dengan mendistribusikan kuisioner kepada seluruh calon responden yang telah ditentukan dalam 
metode sampel penelitian. Sedangkan untuk memperoleh data sekunder yang menyangkut dengan sejarah perusahaan, jumlah karyawan, struktur organisasi dan lain-lain, peneliti mempelajari dokumentasi yang disediakan oleh perusahaan PT. Bank Aceh Syariah baik yang ada di kantor cabang Tapak Tuan, maupun yang berada dikantor pusat di Banda Aceh. Selain itu, data sekunder yang berkaitan dengan konsep dan teori, peneliti mengkaji literatur, buku, jurnal dan majalah yang berkaitan dengan topik penelitian, baik melakukan kunjungan ke pustaka perusahaan, pustaka diperguruan tinggi atau melalui media online/internet. Selain itu, untuk memperoleh data tambahan yang peneliti anggap perlu, peneliti melakukan wawancara dengan beberap orang karyawan di PT. Bank Aceh Syariah Tapak Tuan.

\section{Pengukuran}

Penelitian ini terdiri dari 3 variabel yaitu etika perusahaan, perilaku kewargaan organisasi, dan komitmen organisasi. Variabel etika perusahaan menggunakan 6 indikator (Barnett \& Vaicys, 2010; Jin \& Drozdenko, 2010) kemudian dibuat dalam bentuk 6 pertanyaan dalam kuisioner dengan skala Likert. Variabel $O C B$ diukur dengan 5 indikator yang dituangkan ke dalam 5 pertanyaan menggunakan skala Likert (Purba dan Nina, 2014). Indikator variabel komitmen organisasi diambil berdasarkan dimensi yaitu, (1) Komitmen afektif terdiri dari 8 pertanyaan, (2) komitmen normatif terdiri dari 6 pertanyaan, dan (3) komitmen berkelanjutan terdiri dari 6 pertanyaan (Malthis dan Jackson, 2012). Semua indikator dituangkan dalam bentuk pertanyaan dengan mengunakan skala Likert (dari: sangat tidak setuju $=1$, hingga sangat setuju=5), responden memilih jawaban yang sesuai menurut yang dialami.

\section{Teknik Analisis Data}

Penelitian ini menggunakan teknik analisis jalur (path analysis). Analisis jalur pada merupakan teknik untuk menganalisis hubungan kausalitas yang terjadi pada regresi berganda jika variabel independen mempengaruhi variabel dependen tidak hanya secara langsung, tetapi juga secara tidak langsung (Sarwono, 2014:1). Mengacu pada kerangka pemikiran dan hipotesis penelitian yang sudah dinyatakan sebelumnya, maka analisis jalur dalam penelitian ini menggunakan dua persamaan struktural sebagai berikut.

Persamaan Struktural I :

$$
\mathbf{Z}=\rho \mathbf{z}_{\mathbf{X}}+\varepsilon_{1}
$$

Keterangan :

Z : Komitmen organisasi

$\rho_{\text {zx }}$ : Koefisien jalur etika perusahaan terhadap komitmen organisasi kolektif.

$\varepsilon_{1}:$ Error

Koefisien jalur etika perusahaan terhadap komitmen organisasi kolektif ( $\rho_{\mathrm{YX}}$ ) menunjukkan pengaruh langsung (direct effect) etika perusahaan terhadap komitmen organisasi kolektif.

Persamaan Struktural II :

$\mathrm{Y}=\rho_{\mathrm{YZ}}+\rho_{\mathrm{Y}} \mathrm{X}+\varepsilon_{2}$

Keterangan :

$\mathrm{Y}$ : Perilaku kewargaan organisasi

$\rho_{\text {YZ }}$ : Koefisien jalur komitmen organisasi kolek-

tif terhadap perilaku kewargaan organisasi.

$\rho_{\text {YX }}:$ Koefisien jalur etika perusahaan terhadap perilaku kewargaan organisasi.

$\varepsilon_{2}:$ Error

Koefisien jalur komitmen organisasi terhadap perilaku kewargaan organisasi $\left(\rho_{\text {YZ }}\right)$ menunjukkan pengaruh langsung (direct effect) komitmen organisasi terhadap perilaku kewargaan organisasi. Koefisien jalur persepsi etika perusahaan terhadap perilaku kewargaan organisasi ( $\left.\rho_{\mathrm{YX}}\right)$ menunjukkan besarnya pengaruh langsung etika perusahaan terhadap perilaku kewargaan organisasi.

Untuk mengukur besarnya pengaruh tidak langsung (inderect effect) etika perusahaan (X) terhadap perilaku kewargaan organisasi (Y) melalui komitmen organisasi kolektif (Z) digunakan formula sebagai berikut :

$$
\mathrm{X} \rightarrow Z \rightarrow Y: \rho_{\mathrm{ZX}} \mathrm{X} \rho_{\mathrm{YZ}}
$$

Keterangan :

Y : Perilaku kewargaan organisasi

$\mathrm{Z}$ : Komitmen organisasi kolektif

$\mathrm{X}$ : Etika perusahaan 
$\rho_{\text {zx }}:$ Koefisien jalur etika perusahaan terhadap komitmen organisasi kolektif.

$\rho_{\text {YZ }}$ : Koefisien jalur komitmen organisasi kolektif terhadap perilaku kewargaan organisasi.

\section{HASIL DAN PEMBAHASAN}

\section{Karakteristik Responden}

Karakteristik responden dalam penelitian ini terdiri dari: jenis kelamin, usia, status perkawinan, dan pendidikan terakhir responden. Berdasarkan Tabel 1 menunjukkan bahwa responden dengan jenis kelamin perempuan lebih banyak dibandingkan denga laki-laki. Dilohat dari segi usia di mana responden yang terbanak adalah yang berusia di bawah 35 tahun (42,70\%) dan yang paling sedikit adalah berusia di atas 45 tahun $(5,30 \%)$. Dilihat dari status perkawinan, responden yang telah kawin (menikah) lebih bsnyak dibandingkan dengan yang berstatus belum kawin (78,70\% ; 21,30\%). Pendidikan terakhir responden kebanyakan adalah tamat Diploma dan tamat Sarjana, sedangkan yang tamat SLTA hanya 8 persen dan tamat $\mathrm{S} 2$ sebanyak 1 orang $(1,30 \%)$.

Uji validitas bertujuan untuk melihat apakah skala pengukuran yang dilakukan dapat mengukur apa yang seharusnya diukur (Ghozali, 2012). Uji validitas yang digunakan dalam penelitian ini adalah validitas item, yaitu untuk mengetahui apakah item-item pernyataan yang dimuat dalam kuesioner penelitian valid atau tidak. Pengujian validitas kuesioner didasarkan pada perbandingan nilai $\mathrm{r}$ hitung dan nilai $r$ tabel. Nilai $r$ hitung dicari dengan mencari nilai korelasi antara skor alternatif pilihan jawaban responden pada item pernyataan tertentu dengan total skor item dalam variabel terkait. Selanjutnya nilai korelasi hitung ( $\mathrm{r}$ hitung) tersebut dibandingkan dengan nilai kritis $\mathrm{r}$ product moment ( $\mathrm{r}$ tabel), dengan ketentuan apabila nilai ( $\mathrm{r}$ hitung $>\mathrm{r}$ tabel), maka item pernyataan dalam variabel tertentu dinyatakan valid. Sebaliknya apabila nilai $r$ hitung $<\mathrm{r}$ tabel, maka item pernyataan dalam variabel tertentu dinyatakan tidak valid. Berdasarkan Tabel 2 menunjukkan bahwa semua ukuran dalam kuisioner adalah valid yeng menunjukkan bahwa nilai $\mathrm{r}$ hitung $>\mathrm{r}$ tabel.

Untuk menguji kehandalan kuesioner yang digunakan dalam penelitian ini menggunakan uji reliabilitas. Ukuran standar reliabilitas adalah nilai cronbach alpha yang diperoleh melalui perhitungan statistik. Menurut Sekaran (2006:327), nilai alpha minimum yang diperoleh sebagai syarat kehandalan kuesioner adalah sebesar 0,60. Hal ini berarti bahwa apabila nilai cronbach alpha dibawah 0,60 maka kuesioner belum memenuhi syarat kehandalan. Berdasarkan hasil analisis pengujian reliabilitas pada Tabel 3, menunjukkan bahwa semua variabel memilki nilai cronbach alpha di atas 0,60, maka dapat dikatakan semua kuisioner adalah handal.

Persepsi responden terhadap variabel $O C B$ diperoleh rerata sebesar 3,393, yang berarti sudah mendekati setuju terhadap pertanyaan dalam kuisioner. Rata-rata yang paling kecil adalah 3.450 berada pada pertanyaan" Anda memiliki inisiatif untuk mendukung kelancaran operasional instansi (civic virtue)" yang paling tinggi sebesar 4,190, pada pertanyaan "Anda mau membantu rekan kerja dalam menyelesaikan pekerjaan (altruisme)"

Rerata persepsi responden terhadap variabel etika perusahaan sebesar 4,002, ini menunjukkan semua responden setuju terhadap pertanaan pada variabel tersebut (Tabel 5). Rata yang paling rendah persepsi responden sebesar 3,850 dan yang paling tinggi adalah 4,090, dengan pertanyaan "Bank ini berpartisipasi dalam kegiatan masyarakat (public welfare projects)" dan "Bank ini membantu penyelesaian masalah di lingkungan sosial (resolution of social problems).

Tabel 6 adalah persepsi responden terhadap variabel komitmen organisasi. Rerata persepsi responden sebesar 3,676, ini berarti rata-rata responden hampir setuju terhadap semua pertanyaan tentang komitmen organisasi. Persepsi yang paling rendah terhadap pertanyaan "Anda senang menghabiskan karir di bank ini" sebesar 3,390 dan yang paling tinggi adalah untuk pertanyaan "Bank ini memiliki makna mendalam bagi Anda" yaitu sebesar 4,200.

Tabel 7 menunjukkan pengaruh langsung variabel etika perusahaan terhadap OCB adalah sebesar 0,405 (40,5\%), yang berarti apabila ada peningkatan etika perusahaan 1 persen maka akan berpengaruh terhadap OCB sebesar 40,5 persen dan pengaruh tersebut signifikan pada level 0,000 atau $<0.05$. 
Tabel 1.

Karakteristik Responden

\begin{tabular}{cccr}
\hline No & Uraian & $\begin{array}{c}\text { Frekuensi } \\
\text { (Orang) }\end{array}$ & Persentase \\
\hline 1 & Jenis Kelamin & 35 & \\
& Laki-laki & 40 & 46,70 \\
& Perempuan & & 53,30 \\
\hline 2 & Usia & 32 & \\
& $\leq 35$ tahun & 26 & 42,70 \\
& 36-40 tahun & 13 & 34,70 \\
& $41-45$ tahun & 4 & 17,30 \\
& > 45 tahun & 59 & 5,30 \\
\hline 3 & Status Perkawinan & 16 & 78,70 \\
& Menikah & & 21,30 \\
\hline & Belum Menikah & 6 & \\
\hline 4 & Pendidikan Terakhir & 36 & 8,00 \\
& SLTA & 32 & 42,00 \\
& Diploma & 1 & 1,10 \\
& Sarjana (S1) & & \\
& Pascasarjana (S2) &
\end{tabular}

Sumber: Hasil analisis data primer, 2017

Tabel 2

Hasil Uji Validitas

\begin{tabular}{|c|c|c|c|c|c|}
\hline No & Variabel & $\begin{array}{c}\text { Item } \\
\text { Pernyataan }\end{array}$ & $\begin{array}{l}\text { Nilai R } \\
\text { Hitung }\end{array}$ & $\begin{array}{l}\text { Nilai R Tabel } \\
\quad(n=75)\end{array}$ & Keterangan \\
\hline \multirow[t]{5}{*}{1} & Perilaku Kewargaan & A1 & 0,610 & 0,227 & Valid \\
\hline & Organisasi & $\mathrm{A} 2$ & 0,708 & 0,227 & Valid \\
\hline & & A3 & 0,710 & 0,227 & Valid \\
\hline & & A4 & 0,676 & 0,227 & Valid \\
\hline & & A5 & 0,651 & 0,227 & Valid \\
\hline \multirow[t]{20}{*}{2} & Komitmen Organisasi & B1 & 0,630 & 0,227 & Valid \\
\hline & Kolektif & B2 & 0,397 & 0,227 & Valid \\
\hline & & B3 & 0,428 & 0,227 & Valid \\
\hline & & B4 & 0,214 & 0,227 & Valid \\
\hline & & B5 & 0,613 & 0,227 & Valid \\
\hline & & B6 & 0,539 & 0,227 & Valid \\
\hline & & B7 & 0,356 & 0,227 & Valid \\
\hline & & B8 & 0,473 & 0,227 & Valid \\
\hline & & B9 & 0,389 & 0,227 & Valid \\
\hline & & B10 & 0,453 & 0,227 & Valid \\
\hline & & B11 & 0,508 & 0,227 & Valid \\
\hline & & B12 & 0,628 & 0,227 & Valid \\
\hline & & B13 & 0,619 & 0,227 & Valid \\
\hline & & B14 & 0,360 & 0,227 & Valid \\
\hline & & B15 & 0,401 & 0,227 & Valid \\
\hline & & B16 & 0,453 & 0,227 & Valid \\
\hline & & B17 & 0,401 & 0,227 & Valid \\
\hline & & B18 & 0,607 & 0,227 & Valid \\
\hline & & B19 & 0,506 & 0,227 & Valid \\
\hline & & B20 & 0,545 & 0,227 & Valid \\
\hline \multirow[t]{6}{*}{3} & Etika & C1 & 0,559 & 0,279 & Valid \\
\hline & Perusahaan & $\mathrm{C} 2$ & 0,655 & 0,279 & Valid \\
\hline & & C3 & 0,823 & 0,279 & Valid \\
\hline & & $\mathrm{C} 4$ & 0,739 & 0,279 & Valid \\
\hline & & C5 & 0,683 & 0,279 & Valid \\
\hline & & C6 & 0,498 & 0,279 & Valid \\
\hline
\end{tabular}

Sumber: Hasil analisis data primer, 2017 
Tabel 3

Hasil Uji Reliabilitas Kuesioner

\begin{tabular}{clccc}
\hline No & \multicolumn{1}{c}{ Variabel } & Jumlah Item & Nilai Alpha & Keterangan \\
\hline 1 & Perilaku kewargaan organisasi & 5 & 0,680 & Handal \\
2 & Komitmen organisasi kolektif & 20 & 0,822 & Handal \\
3 & Etika perusahaan & 6 & 0,730 & Handal \\
\hline
\end{tabular}

Sumber: Hasil analisis data primer, 2017.

Tabel 4

Persepsi Responden terhadap Perilaku Kewargaan Organisasi

\begin{tabular}{|c|c|c|c|c|c|c|}
\hline \multirow{2}{*}{$\begin{array}{l}\text { Pernyataan yang Berhubungan dengan } \\
\text { Perilaku Kewargaan Organisasi }\end{array}$} & \multicolumn{5}{|c|}{$\begin{array}{l}\text { Frekuensi Responden Berdasar- } \\
\text { kan Pilihan Jawaban }\end{array}$} & \multirow{2}{*}{$\begin{array}{l}\text { Rata } \\
\text { Rata } \\
\text { Skor }\end{array}$} \\
\hline & $\begin{array}{l}\text { STS } \\
\text { (1) }\end{array}$ & $\begin{array}{l}\text { TS } \\
(2)\end{array}$ & $\begin{array}{l}\text { KS } \\
(3)\end{array}$ & $\begin{array}{c}S \\
(4)\end{array}$ & $\begin{array}{l}\text { ss } \\
(5)\end{array}$ & \\
\hline $\begin{array}{l}\text { 1. Anda mau membantu rekan kerja dalam menyelesaikan } \\
\text { pekerjaan (altruisme). }\end{array}$ & - & - & 9 & 43 & 23 & 4,190 \\
\hline $\begin{array}{l}\text { 2. Anda mau mendorong rekan kerja untuk bekerja lebih giat } \\
\text { (courtesy). }\end{array}$ & - & 4 & 8 & 51 & 12 & 3,950 \\
\hline $\begin{array}{l}\text { 3. Anda menerima kondisi atau keadan yang kurang ideal di } \\
\text { tempat kerja (sportmanship). }\end{array}$ & - & 1 & 11 & 41 & 22 & 4,120 \\
\hline $\begin{array}{l}\text { 4. Anda memiliki inisiatif untuk mendukung kelancaran opera- } \\
\text { sional instansi (civic virtue). }\end{array}$ & 2 & 13 & 16 & 37 & 7 & 3,450 \\
\hline $\begin{array}{l}\text { 5. Anda tidak membuang-buang waktu di tempat kerja dan } \\
\text { secara sukarela bersedia melakukan pekerjaan yang tidak } \\
\text { menjadi tanggung jawab (conscientiousness atau geralized } \\
\text { compliance). }\end{array}$ & - & 7 & 9 & 40 & 19 & 3,950 \\
\hline Rerata Skor & & & & & & 3,931 \\
\hline
\end{tabular}

Sumber: Hasil analisis data primer, 2017.

Tabel 5

Persepsi Responden terhadap Etika Perusahaan

\begin{tabular}{|c|c|c|c|c|c|c|}
\hline \multirow{2}{*}{$\begin{array}{c}\text { Pernyataan yang Berhubungan dengan } \\
\text { Etika Perusahaan }\end{array}$} & \multicolumn{5}{|c|}{$\begin{array}{l}\text { Frekuensi Responden Berdasar- } \\
\text { kan Pilihan Jawaban }\end{array}$} & \multirow{2}{*}{$\begin{array}{l}\text { Rata } \\
\text { Rata } \\
\text { Skor }\end{array}$} \\
\hline & $\begin{array}{l}\text { STS } \\
\text { (1) }\end{array}$ & $\begin{array}{l}\text { TS } \\
(2)\end{array}$ & $\begin{array}{l}\text { KS } \\
(3)\end{array}$ & $\begin{array}{c}S \\
(4)\end{array}$ & $\begin{array}{l}\text { SS } \\
(5)\end{array}$ & \\
\hline $\begin{array}{l}\text { 1. Bank ini berpartisipasi dalam kegiatan masyarakat (public } \\
\text { welfare projects) }\end{array}$ & - & 2 & 21 & 38 & 14 & 3,850 \\
\hline $\begin{array}{l}\text { 2. Bank ini membantu penyelesaian masalah di lingkungan } \\
\text { sosial (resolution of social problems). }\end{array}$ & - & - & 8 & 52 & 15 & 4,090 \\
\hline $\begin{array}{l}\text { 3. Karyawan bank ini diharapkan dapat bekerja secara profe- } \\
\text { sional. }\end{array}$ & - & - & 14 & 46 & 15 & 4,010 \\
\hline $\begin{array}{l}\text { 4. Nilai etika yang berlaku pada bank ini lebih dari sekedar } \\
\text { kinerja ekonomi. }\end{array}$ & - & 2 & 13 & 38 & 22 & 4,070 \\
\hline 5. Karyawan bank ini dipandu untuk memiliki etika yang baik. & - & 1 & 15 & 49 & 10 & 3,910 \\
\hline $\begin{array}{l}\text { 6. Karyawan bank ini didorong untuk mengembangkan keprib- } \\
\text { adian personal yang baik }\end{array}$ & - & - & 15 & 39 & 21 & 4,080 \\
\hline Rerata Skor & & & & & & 4,002 \\
\hline
\end{tabular}

Sumber: Hasil analisis data primer, 2017. 
Tabel 6

Persepsi Responden terhadap Komitmen Organisasi

\begin{tabular}{|c|c|c|c|c|c|c|}
\hline \multirow{2}{*}{$\begin{array}{l}\text { Pernyataan yang Berhubungan dengan } \\
\text { Komitmen Organisasi Kolektif }\end{array}$} & \multicolumn{5}{|c|}{$\begin{array}{l}\text { Frekuensi Responden Berdasar- } \\
\text { kan Pilihan Jawaban }\end{array}$} & \multirow{2}{*}{$\begin{array}{l}\text { Rata } \\
\text { Rata } \\
\text { Skor }\end{array}$} \\
\hline & $\begin{array}{l}\text { STS } \\
(1)\end{array}$ & $\begin{array}{l}\text { TS } \\
(2)\end{array}$ & $\begin{array}{l}\text { KS } \\
(3)\end{array}$ & $\begin{array}{l}S \\
(4)\end{array}$ & $\begin{array}{l}\text { SS } \\
(5)\end{array}$ & \\
\hline \multicolumn{7}{|l|}{ Komitmen afektif } \\
\hline 1. Anda senang menghabiskan karir di bank ini. & 3 & 12 & 18 & 37 & 5 & 3,390 \\
\hline $\begin{array}{l}\text { 2. Anda senang membicarakan bank ini bersama rekan kerja } \\
\text { saat sedang tidak bekerja }\end{array}$ & - & 10 & 18 & 44 & 43 & 3,530 \\
\hline $\begin{array}{l}\text { 3. Anda merasa masalah yang dihadapi bank ini adalah ma- } \\
\text { salah Anda juga }\end{array}$ & - & 8 & 21 & 37 & 9 & 3,630 \\
\hline 4. Anda merasa mudah beradaptasi saat bekerja di bank ini. & - & 4 & 12 & 53 & 6 & 3,810 \\
\hline 5. Anda merasa bahwa bank ini dan orang-orang di dalamnya & 1 & 13 & 18 & 38 & 5 & 3,440 \\
\hline $\begin{array}{l}\text { 6. Anda merasa sangat menyatu secara emosional dengan } \\
\text { bank ini. } \\
\text { 7. Bank ini memiliki makna mendalam bagi Anda. }\end{array}$ & - & 4 & 18 & 45 & 8 & 3,760 \\
\hline 8. Anda merasa menjadi bagian dari bank ini. & - & 1 & 5 & 47 & 22 & 4,200 \\
\hline Komitmen Normatif & - & 7 & 15 & 45 & 8 & 3,720 \\
\hline $\begin{array}{l}\text { 9. Anda merasa memiliki kewajiban saat menjadi karyawan } \\
\text { bank ini. }\end{array}$ & - & 10 & 17 & 45 & 3 & 3,550 \\
\hline $\begin{array}{l}\text { 10. Anda merasa memiliki banyak keuntungan selama bekerja } \\
\text { di bank ini. }\end{array}$ & - & 9 & 20 & 42 & 4 & 3,550 \\
\hline $\begin{array}{l}\text { 11. Anda akan merasa bersalah apabila meninggalkan bank } \\
\text { ini. } \\
\text { 12. Bank ini layak untuk mendapat loyalitas karyawannya. }\end{array}$ & - & 4 & 19 & 38 & 14 & 3,830 \\
\hline $\begin{array}{l}\text { 12. Bank ini layak untuk mendapat loyalitas karyawannya. } \\
\text { 13. Anda tidak akan meninggalkan bank ini karena masih mim- }\end{array}$ & - & 6 & 19 & 39 & 11 & 3,730 \\
\hline $\begin{array}{l}\text { iliki kewajiban. } \\
\text { 14. Anda berhutang banyak pada bank ini. }\end{array}$ & - & 2 & 25 & 46 & 2 & 3,640 \\
\hline Komitmen Berkelanjutan & - & 6 & 15 & 52 & 2 & 3,670 \\
\hline $\begin{array}{l}\text { 15. Anda khawatir apabila berhenti dari bank ini karena belum } \\
\text { memiliki tempat kerja pengganti }\end{array}$ & - & 2 & 16 & 48 & 9 & 3,850 \\
\hline $\begin{array}{l}\text { 16. Akan sangat susah bagi Anda untuk meninggalkan bank ini } \\
\text { walaupun Anda menginginkannya. }\end{array}$ & - & 7 & 15 & 47 & 6 & 3,690 \\
\hline $\begin{array}{l}\text { 17. Kehidupan Anda akan kacau apabila memutuskan untuk } \\
\text { meninggalkan bank ini. }\end{array}$ & - & 12 & 18 & 42 & 3 & 3,480 \\
\hline 18. Anda merasa butuh untuk bekerja di bank ini. & & & & & & \\
\hline $\begin{array}{l}\text { 19. Anda tidak punya banyak pilihan sehingga tidak berpikir } \\
\text { meninggalkan bank ini. }\end{array}$ & - & $\begin{array}{c}10 \\
3\end{array}$ & $\begin{array}{l}18 \\
27\end{array}$ & $\begin{array}{l}37 \\
44\end{array}$ & $\begin{array}{c}10 \\
1\end{array}$ & $\begin{array}{l}3,630 \\
3,570\end{array}$ \\
\hline $\begin{array}{l}\text { 20. Anda sudah memberikan upaya yang optimal saat bekerja } \\
\text { di bank ini, sehingga tetap mau bekerja. }\end{array}$ & - & 2 & 21 & 38 & 14 & 3,850 \\
\hline Rerata Skor & & & & & & 3,676 \\
\hline
\end{tabular}

Sumber: Hasil analisis data primer, 2017.

Tabel 7

Nilai koefisien jalur pengaruh etika perusahaan terhadap komitmen organisasi

Coefficientsa

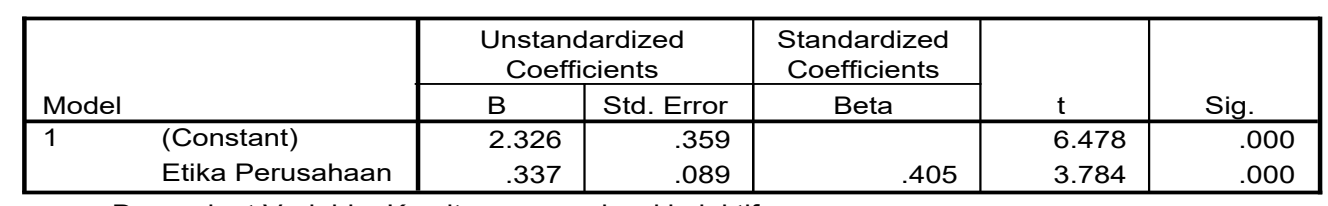

a. Dependent Variable: Komitmen organisasi kolektif

Sumber: Hasil analisis data primer, 2017. 
Tabel 8 menunjukkan pengaruh mediasi (variabel komitmen organisasi) terhadap pengaruh etika perusahaan dan $O C B$. Besarnya pengaruh mediasi dapat dilihat pada Tabel 9.

Gambar 2 memperlihatkan secara jalur baik pengaruh lagsung dan pengaruh dengan mediasi variabel komitmen organisasi, serta pengaruh kausalitas antar variabel.

\section{Implikasi Teoritis}

Hasil penelitian ini menunjukkan adanya pengaruh secara positif dan signifikan etika perusahaan terhadap komitmen organisasi. Hasil penelitian memberikan dukungan terhadap penelitian sebelumnya dan pendapat pakar tentang pengaruh kedua variabel tersebut (Robert \& Dowling, 2012) dan (Sharma et al., 2013) yang menyatakan bahwa etika perusahaan dapat berkontribusi positif terhadap pembentukan komitmen organisasi dikalangan karyawan perusahaan. Singhapakdi et al. (2013) juga menyatakan bahwa etika perusahaan dapat memperkuat komitmen karyawan terhadap perusahaan tempat mereka bekerja.

Selanjutnya temuan penelitian ini yang menyimpulkan adanya pengaruh positif dan signifikan komitmen organisasi kolektif terhadap perilaku kewargaan organisasi sesuai dengan pendapat Podsakoff et al. (2012) yang menyatakan bahwa ketika karyawan memperlihatkan komitmen yang tinggi terhadap organisasi tempat mereka bekerja, mereka cenderung berkontribusi ekstra terhadap perusahaan dan mau melaksanakan pekerjaan melebihi beban kerja yang diberikan kepada mereka. Organ et al. (2012) menyatakan bahwa komit- men organisasi merupakan salah satu determinan penting bagi perilaku kewargaan organisasi.

Adanya peran komitmen organisasi sebagai variabel intervening antara etika perusahaan dan perilaku kewargaan organisasi konsisten dengan temuan penelitian Chun et al. (2013) yang menyimpulkan bahwa komitmen organisasi bertindak sebagai faktor intervening yang menjelaskan hubungan antara etika perusahaan dengan perilaku karyawan. Temuan penelitian ini mendukung temuan penelitian Baker et al. (2012) yang menyimpulkan bahwa dalam hubungan antara etika perusahaan dengan $O C B$, komitmen organisasi dapat berperan sebagai mediator variabel.

\section{Implikasi Manajerial}

Adanya pengaruh positif dan signifikan etika perusahaan terhadap komitmen organisasi kolektif dan perilaku kewargaan organisasi berimplikasi bahwa upaya peningkatan perilaku kewargaan organisasi dikalangan karyawan PT. Bank Aceh Syariah Tapak Tuan dapat dilakukan melalui upaya peningkatan etika perusahaan tersebut. Selain itu, temuan penelitian yang memberikan bukti empiris tentang peran komitmen organisasi sebagai variabel intervening antara perilaku kewargaan organisasi dan etika perusahaan berimplikasi bahwa upaya peningkatan komitmen organisasi atau rasa keterikatan karyawan terhadap perusahaan jasa keuangan bank tersebut harus dilakukan oleh yang pemangku yang berwenang guna membentuk perilaku kewargaan organisasi. Melalui komitmen organisasi, pengaruh positif etika perusahaan terhadap perilaku kewargaan organisasi menjadi lebih besar. 
Tabel 8

Nilai Koefisien Jalur Pengaruh Etika Perusahaan dan Komitmen Organisasi terhadap Perilaku Kewargaan Organisasi

\begin{tabular}{|c|c|c|c|c|c|c|c|c|}
\hline \multicolumn{9}{|c|}{ Coefficientsa } \\
\hline & & \multicolumn{2}{|c|}{$\begin{array}{c}\text { Unstandardized } \\
\text { Coefficients }\end{array}$} & $\begin{array}{l}\text { Standardized } \\
\text { Coefficients }\end{array}$ & \multirow[b]{2}{*}{$\mathrm{t}$} & \multirow[b]{2}{*}{ Sig. } & \multicolumn{2}{|c|}{ Collinearity Statistics } \\
\hline \multicolumn{2}{|c|}{ Model } & B & Std. Error & Beta & & & Tolerance & VIF \\
\hline \multirow[t]{3}{*}{1} & (Constant) & 1.024 & .618 & & 1.658 & .102 & & \\
\hline & $\begin{array}{l}\text { Komitmen } \\
\text { organisasi kolektif }\end{array}$ & .506 & .160 & .355 & 3.153 & .002 & .836 & 1.196 \\
\hline & Etika Perusahaan & .262 & .130 & .220 & 2.015 & .043 & .836 & 1.196 \\
\hline
\end{tabular}

a. Dependent Variable: Perilaku Kewargaan Organisasi

Sumber: Hasil analisis data primer, 2017.

Tabel 9

Pengaruh Langsung dan Tidak Langsung Etika Perusahaan Terhadap Perilaku Kewargaan Organisasi/ $O C B$

\begin{tabular}{llcc}
\hline \multicolumn{1}{c}{\begin{tabular}{c}
\multicolumn{1}{c}{ Bentuk } \\
Pengaruh
\end{tabular}} & \multicolumn{1}{c}{ Variabel yang Dianalisis } & \multicolumn{1}{c}{$\begin{array}{c}\text { Koefisien } \\
\text { jalur }\end{array}$} & $\begin{array}{c}\text { Besarnya } \\
\text { Pengaruh }\end{array}$ \\
\hline $\begin{array}{l}\text { Pengaruh langsung } \\
\text { (direct effect) }\end{array}$ & $\begin{array}{l}\text { Etika Perusahaan (X) Terhadap } \\
\text { Komitmen Organisasi Kolektif (Z) }\end{array}$ & 0,405 & $16,4 \%$ \\
& $\begin{array}{l}\text { Komitmen Organisasi Kolektif (Z) terhadap Per- } \\
\text { ilaku Kewargaan Organisasi (Y) }\end{array}$ & 0,355 & $12,6 \%$ \\
& Etika Perusahaan (X) Terhadap & $4,84 \%$ \\
\hline $\begin{array}{l}\text { Pengaruh tidak } \\
\text { langsung (indirect } \\
\text { effect) }\end{array}$ & $\begin{array}{l}\text { Etika Perusahaan (X) Terhadap } \\
\text { Perilaku Kewargaan Organisasi (Y) Melalui Komit- } \\
\text { men Organisasi Kolektif }\end{array}$ & 0,220 & $14,38 \%$ \\
\hline
\end{tabular}

$$
\mathrm{pYX}=0,220
$$

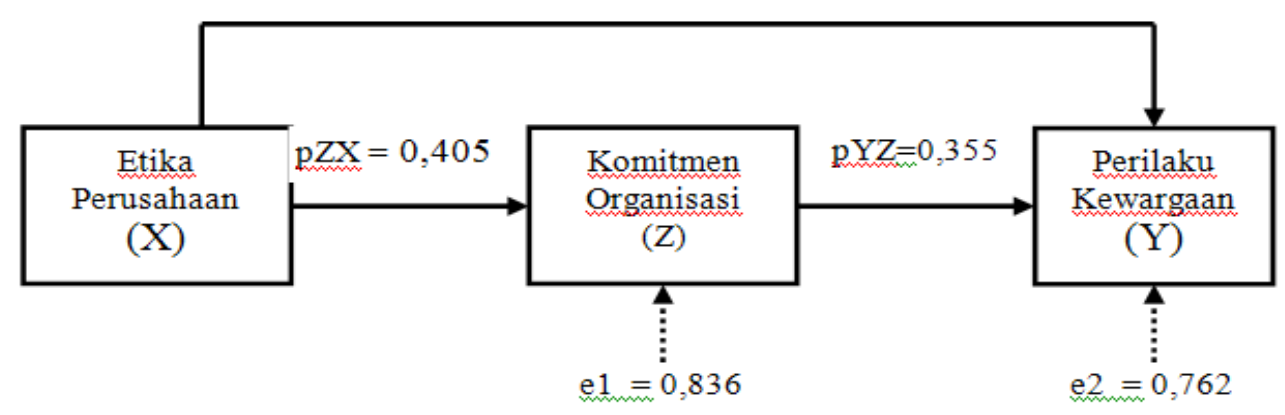

Gambar 2. Hasil analisis pengaruh langsung dan pengaruh mediasi terhadap variabel $O C B$ 


\section{REFERENSI}

Allen, N. J., \& Meyer, J. P. (2010). The measurement and antecedents of affective, continuance, and normative commitment to the organization. Journal of Occupational Psychology, 63, 1-18.

Azwar, S. (2015). Sikap Manusia Teori dan Pengukurannya, Edisi Kedua, Pustaka Pelajar, Yogyakarta.

Bai, Q., Lin, W., \& Wang, L. (2016). Family incivility and counterproductive work behavior: A moderated mediation model of self-esteem and emotional regulation. Journal of Vocational Behavior, 94, 11-19.

Baker, T. L., Hunt, T. G., \& Andrews, M. C. (2012). Promoting ethical behavior and organizational citizenship behaviors: The influence of corporate ethical values. Journal of Business Research, 59(7), 849-857.

Barnett, T., \& Vaicys, C. (2010). The moderating effect of individuals' perceptions of ethical work climate on ethical judgments and behavioral intentions. Journal of Business Ethics, 27: 351-362.

Chun, J. S., Shin, Y., Choi, J. N., \& Kim, M. S. (2013). How does corporate ethics contribute to firm financial performance? The mediating role of collective organizational commitment and organizational citizenship behavior. Journal of Management, 39(4), 853-877.

Cullen, J. B., Parboteeah, K. P., \& Victor, B. (2013). The effects of ethical climates on organizational commitment: A two-study analysis. Journal of Business Ethics, 46: 127-141.

Diricana, A. H., \& Erdilb, O. (2016). An Exploration of Academic Staff's Organizational Citizenship Behavior and Counterproductive Work Behavior in Relation to Demographic Characteristics.12th International Strategic Management Conference, ISMC 2016, 28-30 October 2016, Antalya,Turkey. Social and Behavioral Sciences, 235, $351-360$.

Gunara, A., Ali, M., dan Haerini, S. (2014). Analisis Pengaruh Kepemimpinan Transformasional, Kepuasan Kerja dan Komitmen Organisasional Terhadap Perilaku Kewargaan Organisasi di PT. INCO Tbk, Jurnal Manajemen dan Bisnis, 2(2), 125-137.

Huang, J., dan Yang (2014) Satisfaction with Business-to-Employee Benefit System and Organizational Citizenship Behavior, International Journal of Manpower, 25, 125-137.

Hunt, S. D., Wood, V. R., \& Chonko, L. B. (2013). Corporate ethical values and organizational commitment in marketing. Journal of Marketing, 53, 79-90.

Jin, K. G., \& Drozdenko, R. G. (2010). Relationships among perceived organizational core values, corporate social responsibility, ethics, and organizational performance outcomes: An empirical study of information technology professionals. Journal of Business Ethics, 92: 341-359.

Kapstein, M. (2014). Business Codes of Multinational Firms: What Do They Say ?, Journal of Business Ethics, 50(1), 13-31. 
Kreitner, R., dan Kanicki, A. (2015). Perilaku Organisasi: Organizational Behavior, Buku I, Edisi 5, Terjemahan: Ely Suandy, Salemba Empat, Jakarta.

Kuncoro, M. (2013). Metode Riset Untuk Bisnis dan Ekonomi: Bagaimana Meneliti dan Menulis Tesis ? Jakarta, Erlangga..

Luthans, F. (2013). Organizational Behavior, Seventh Edition. McGraw-Hill, Inc.

Malhotra, N. K. (2015). Riset Pemasaran: Pendekatan Terapan, Alih Bahasa, Rusyadi Maryam, Edisi Ketujuh, Jakarta, Indeks.

Malthis, Robert L. dan Jackson, John H. (2012) Manajemen Sumber Daya Manusia. Salemba Empat, Jakarta.

Meyer, J. P., Stanley, D. J., Herscovitch, L., \& Topolnytsky, L. (2012). Affective, continuance, and normative commitment to the organization: A meta-analysis of antecedents, correlates, and consequences. Journal of Vocational Behavior, 61(1), 20-52.

Meyer, J. P., \& Allen, N. J. (2011). Commitment in the Workplace: Theory, Research, and Application. Thousand Oaks, CA: Sage Publications.

Mossholder, K. W., Richardson, H. A., \& Settoon, R. P. (2011). Human resource systems and helping in organizations: A relational perspective. Academy of Management Review, 36: 33-52.

Nachrowi, D. dan Usman, H. (2012). Penggunaan Teknik Ekonometri: Pendekatan Populer dan Praktis Dilengkapi Teknik Analisis dan Pengolahan Data Dengan Menggunakan Paket SPSS, Edisi Revisi, PT Rajagrafindo Persada, Jakarta.

Organ, D. W., Podsakoff, P. M., \& MacKenzie, S. B. (2012). Organizational citizenship behavior: Its nature, antecedents, and consequences. Thousand Oaks, CA: Sage.

Podsakof, P \& Boomer W. H (2010) Tranformational Leader Behaviors and Substitutes for Leadership As Determinants of Employee Satisfaction/ Commitment, Trust and Organizational Citizenship Behaviors, Journal of Management, 22 (2) 259-298.

Podsakoff, P. M., MacKenzie, S. B., Paine, J. B., \& Bachrach, D. G. (2012). Organizational citizenship behaviors: A critical review of the theoretical and empirical literature and suggestions for future research. Journal of Management, 26, 513-563.

Purba, Eflina dan Ali Nina (2014) Pengaruh Kepribadian dan Komitmen Organisasi Terhadap Organizational Citizenship Behavior, Makara, Sosial Humaniora, 8(3), 105-111.

Robbins, S.P. (2012) Organizational Behavior, (9 ${ }^{\text {th }}$ ed). New Jersey: Prentice-Hall.

Roberts, P. W., \& Dowling, G. R. (2012). Corporate reputation and sustained superior financial performance. Strategic Management Journal, 23, 1077-1093. 
Saleem, F. (2014). Impact of Corporate Ethical Values on Employees' Behaviour: Mediating Role of Organizational Commitment Farida Saleem, Pakistan Journal of Psychological Research, 29 (1), 245-263.

Santosa, P., dan Ashari. (2012). Analisis Statistik Dengan Microsoft Excel \& SPSS, Yogyakarta, Andi.

Santoso, S. (2010). SPSS Mengolah Data Statistik Secara Profesional, Jakarta, Alex Media Komputindo.

Sarwono, J. (2014). Analisis Jalur Untuk Riset Bisnis Dengan SPSS, Penerbit Andi, Yogyakarta.

Schwepker Jr., C. H. (2011). Ethical climate's relationship to job satisfaction, organizational commitment, and turnover intention in the salesforce. Journal of Business Research, 54(1), 39-52.

Sharma, D., Borna, S., \& Stearns, J. M. (2013). An investigation of the effects of corporate ethical values on employee commitment and performance: Examining the moderating role of perceived fairness. Journal of Business Ethics, 89(2), 251-260.

Singhapakdi, A., Vitell, S. J., \& Franke, G. R. (2013). Antecedents, consequences, and mediating effects of perceived moral intensity and personal moral philosophies. Journal of the Academy of Marketing Science, 27(1), 19-36.

Soetjipto, Budi. W dan Firdaus Noor. (2013). Memodifikasi Perilaku, Manajemen Usahawan Indonesia, No. 02 TH XXXII Februari.

Sopiah. (2014). Perilaku Organisasi, Yokyakarta, Penerbit Andi.

Suliyanto. (2012). Metode Riset Bisnis, Yokyakarta, Penerbit Andi.

Sumodiningrat, Gunawan. (2014). Ekonometrika Pengantar, Yokyakarta, BPFE-UGM.

Trevino, L. K., Butterfield, K. D., \& McCabe, D. L. (2013). The ethical context in organizations: Influences on employee attitudes and behaviors. Business Ethics Quarterly, 8: 447-476.

Tsai, M. T., \& Huang, C. C. (2014). The relationship among ethical climate types, facets of job satisfaction, and the three components of organizational commitment: A study of nurses in Taiwan. Journal of Business Ethics, 80, 565-581.

Umar, H. (2015). Metode Penelitian Untuk Skripsi dan Tesis Bisnis, PT. Gramedia, Jakarta.

Victor, B., \& Cullen, J. B. (2014). The organizational bases of ethical work climates. Administrative Science Quarterly, 33, 101-125.

Wijayanto, B., dan Gugup Kismono (2014) The Effect of Job Embeddedness on Organizational Citizenship Behavior: The Mediating Role of Sense of Responsibility, Gadjah Mada International Journal of Business, 6, 335-354. 